JURNAL GEOGRAFI

Geografi dan Pengajarannya

ISSN 1412 - 6982

e-ISSN : 2443-3977

Volume XVII Nomor 2 Desember 2019

\title{
IMPLEMENTASI TPACK FRAMEWORK DALAM WORKSHOP SSP PROGRAM PPG UNTUK GURU GEOGRAFI PROFESIONAL
}

\author{
${ }^{1}$ Mega Prani Ningsih, ${ }^{2}$ Dewi Puspa Arum \\ ${ }^{1}$ Universitas Siliwangi, \\ Jl. Siliwangi No.24, Kahuripan, Kec. Tawang, Tasikmalaya, Jawa Barat, 46115 \\ ${ }^{2}$ Universitas Pembangunan Nasional "Veteran" Jawa Timur, \\ Jl. Rungkut Madya No.1, Kec. Gn. Anyar, Kota Surabaya, Jawa Timur, 60294
}

\begin{abstract}
Abstrak : Program PPG merupakan pendidikan untuk mencetak guru yang kompeten dan professional. Program PPG SM 3T pertama kali dilaksanakan oleh Universitas Negeri Malang (UM) dan Universitas Negeri Surabaya (Unesa). Workshop SSP sebagai bagian Program PPG dalam model kolaboratif di UM dan Unesa belum secara menyeluruh menerapkan kerangka TPACK. Hal ini berdampak pada lulusan yang belum terlatih membuat media pembelajaran berbasis teknologi digital. Penelitian ini merupakan penelitian deskriptif melalui pendekatan kualitatif dengan desain studi kasus di UM dan Unesa pada Prodi Pendidikan Geografi. Data penelitian terdiri dari data primer berupa informan kunci dan data sekunder berupa dokumen Program PPG. Teknik pengumpulan data melalui wawancara mendalam dan dokumentasi. Analisis data menggunakan model interaksi Miles dan Huberman. Hasil penelitian ini menunjukkan bahwa pembelajaran melalui blended learning menjadi salah satu alternatif yang dapat diterapkan untuk mengolaborasikan pembelajaran konvensional dan modern berbasis teknologi digital. Proses belajar dapat dilakukan secara offline dan online. Oleh karena itu, calon guru perlu mempelajari, menciptakan, dan menggunakan berbagai teknologi digital yang ada dalam pembelajaran blended learning.
\end{abstract}

Kata kunci : PPG, guru geografi, TPACK, blended learning, teknologi digital

\section{A. PENDAhuluan}

Dunia telah berada pada era perkembangan industri 4.0, masa perkembangan teknologi informasi dan komunikasi yang sangat pesat. Scawab dalam Putrawangsa (2018) menyatakan bahwa revolusi industri 4.0 ditandai dengan adanya pemanfaatan kecerdasan buatan (artificial inteligent) dan digitalisasi di berbagai bidang kehidupan termasuk dalam bidang pendidikan. Pernyataan senada juga disampaikan oleh Hoyles \& Lagrange (2010) yang menegaskan bahwa sistem pendidikan saat ini sangat dipengaruhi oleh perkembangan teknologi. Hal ini menandakan bahwa bidang pendidikan harus dapat beradaptasi dengan penggunaan teknologi informasi dan komunikasi dalam segala lini.

Perkembangan teknologi informasi dan komunikasi dalam era revolusi 
industri 4.0 secara langsung maupun tidak langsung telah mempengaruhi sistem pendidikan di Indonesia. Salah satu unsur terpenting dalam menentukan tercapainya tujuan pendidikan nasional di Indonesia ialah guru. Guru memiliki peranan penting dalam mengeksekusi tujuan pendidikan nasional seperti yang tertuang dalam UU No. 20 Tahun 2003 dan UU No. 14 Tahun 2005. Peranan penting seorang guru berdasarkan undang-undang tersebut, yaitu guru sebagai pendidik, pengajar, pembimbing, pengarah, pelatih, penilai dan pengevaluasi dari peserta didik (Ristekdikti, 2016).

Pendidikan nasional bertujuan untuk mengembangkan potensi peserta didik agar menjadi manusia yang beriman dan bertakwa kepada Tuhan Yang Maha Esa, berakhlak mulia, sehat, berilmu, cakap, kreatif, mandiri, dan menjadi warga negara yang demokratis serta bertanggung jawab (Ristekdikti, 2016). Tujuan pendidikan nasional tersebut sejalan dengan tuntutan pembelajaran abad 21, masa berlangsungnya era revolusi industri 4.0. Apandi dalam Hidayat dan Utami (2019) menyampaikan bahwa setidaknya ada empat hal yang tecermin dalam pembelajaran abad 21, yaitu berpikir kritis, kreativitas, komunikasi, dan kolaborasi. Empat hal tersebut merupakan hal penting yang harus ada dalam pendidikan agar potensi peserta didik dapat berkembang, sehingga tujuan pendidikan nasional dapat tercapai.

Tujuan pembelajaran nasional seperti yang disampaikan sebelumnya sejalan dengan tuntutan pembelajaran abad 21. Anderson dan Karthwohl (2008) menegaskan bahwa terdapat enam poin untuk dapat menghadapi tuntutan pembelajaran di abad 21 agar setiap guru mengalami peningkatan kemampuan pasar, kemampuan bekerja, dan kesiapan warga negara. Enam poin tersebut dapat dicapai melalui berpikir kritis, multidisiplin, kreativitas, berkomunikasi dengan baik, inovatif, dan bertanggung jawab. Guru di Indonesia wajib memiliki kemampuankemampuan tersebut untuk dapat bersaing di ranah global dalam era revolusi industri 4.0.

Guru geografi ialah bagian dari sumber daya manusia dalam sistem pendidikan. Kesiapan guru geografi dalam menyampaikan materi pembelajaran di kelas merupakan hal yang sangat penting. Berbagai kegiatan pelatihan telah dilakukan oleh pemerintah untuk memperbaiki kualitas dan membangun kompetensi guru geografi menjadi profesional. Salah satu kebijakan pemerintah untuk meningkatkan kualitas dan kompetensi guru geografi agar lebih profesional adalah Program PPG (Pendidikan Profesi Guru). Melalui program PPG, 
seluruh guru pada umumnya dan guru geografi pada khususnya diharapkan mengalami perbaikan kompetensi sehingga tercapai peningkatan kualitas pembelajaran.

Ristekdikti (2017) menyatakan bahwa Program PPG adalah program pendidikan yang diselenggarakan bagi lulusan S-1 Kependidikan dan S-1/D-IV Non-Kependidikan yang memiliki bakat dan minat menjadi guru. Program ini bertujuan agar mereka dapat menjadi guru profesional setelah memenuhi syarat-syarat tertentu sesuai dengan standar nasional pendidikan dan memperoleh sertifikat pendidik (Ristekdikti, 2017). Penelitian Ningsih (2016) menunjukkan bahwa Program PPG untuk guru geografi mulai dilaksanakan tahun 2013 untuk para sarjana program $3 \mathrm{~T}$, sehingga program PPG yang dilaksanakan dikenal dengan Program PPG SM 3T.

Lebih mendetail mengenai program ini, Ningsih (2016) menjelaskan bahwa pelaksanaan Program PPG SM 3T kali pertama dilaksanakan di dua LPTK (Lembaga Pendidikan Tenaga Kependidikan) yang ditunjuk oleh Ristekdikti sebagai pengelola, yaitu Universitas Negeri Malang (UM) dan Universitas Negeri Surabaya (Unesa). Pelaksanaan Program PPG di UM dimulai tahun 2013 dan Unesa pada tahun 2014. Selanjutnya, kedua LPTK tersebut melaksanakan Program PPG pada tahun yang sama yaitu tahun 2015 .

Guru geografi alumni SM 3T sebagai peserta Program PPG SM 3T tentunya memiliki tantangan dalam menjalankan pembelajaran di Program PPG SM 3T. Mereka dihadapkan pada tuntutan penguasaan keterampilan pembelajaran abad 21 setelah satu tahun lamanya mengabdi di daerah 3T. Sementara itu, selama satu tahun para guru geografi mengabdi di daerah $3 \mathrm{~T}$ yang secara keruangan sangat terbatas dari akses perkembangan teknologi informasi dan komunikasi. Selanjutnya, guru geografi yang telah kembali dari program SM 3T bertindak kembali selayaknya peserta didik dalam Program PPG SM 3T yang perlu mempelajari dan menguasai kembali kompetensi guru geografi di abad 21 dalam era revolusi industri 4.0.

Triling dan Fadel (2009) menyatakan ada beberapa kecakapan yang harus dimiliki peserta didik generasi abad 21 seperti rasa keingintahuan tinggi, kepercayaan tinggi, keberanian, keterampilan belajar, inovasi, dan keahlian literasi digital, serta memiliki kecakapan hidup dan karir. Kecakapan pembelajaran abad 21 sesuai dengan dengan kompetensi guru geografi yang harus dikuasai oleh peserta Program PPG, yaitu kompetensi pedagogik, kepribadian, sosial, dan profesional. 
Ningrum (2017) menjelaskan lebih spesifik tentang kompetensi profesional yang harus dikuasai oleh guru, yaitu membuat RPP, penguasaan materi, media dan sumber belajar, metode pembelajaran, melaksanakan tes awal dan tes akhir serta pola interaksi proses pembelajaran. Kompetensi profesional yang harus dikuasai oleh guru ini merupakan bagian dari materi-materi yang ada di dalam program PPG, sehingga diharapkan kompetensi profesional guru geografi semakin meningkat.

Kecakapan abad 21 dan kompetensi guru geografi dilatih dalam pembelajaran yang dikemas dalam Program PPG baik di UM maupun di Unesa. Ningsih (2016) dalam tesis yang berjudul Implementasi Program PPG dalam Membangun Kompetensi Guru Geografi (Studi Multi Situs di UM dan Unesa pada Peserta Alumni SM 3T), menemukan model implementasi Program PPG yang disebut model kolaborasi. Model kolaborasi Program PPG tersebut menunjukkan bahwa sistem pembelajaran yang dilakukan terdiri atas tahap workshop SSP (Subject Specific Pedagogy), PPL (Praktik Pengalaman Lapangan) dan uji kompetensi. Artikel ini lebih spesifik membahas mengenai tahap workshop SSP dalam membangun kompetensi guru geografi profesional.
Ningsih (2016) memaparkan lebih spesifik hasil temuan lintas situs mengenai kegiatan dalam workshop SSP di UM dan Unesa. Ada beberapa tahapan kegiatan dalam workshop SSP, antara lain (1) pleno 2, yaitu pendalaman materi kurikulum 2013; (2) pre-test; (3) diskusi kelompok, yaitu diskusi materi geografi dan pedagogik yang belum dipahami; (4) kerja kelompok atau kerja mandiri, yaitu menyusun perangkat pembelajaran (silabus, RPP, media pembelajaran, bahan ajar, LKS, dan penilaian yang beracuan kepada kurikulum 2013); (5) gabungan pleno 3, revisi dan persetujuan RPP yaitu peer teaching internal dan eksternal, ujian formatif terjadwal; dan (6) KKL dan melakukan kegiatan insidental seperti menulis jurnal serta artikel ilmiah. Berdasarkan tahapan kegiatan tersebut, workshop SSP bertujuan menyiapkan peserta agar mampu mengembangkan perangkat pembelajaran yang mendidik, sehingga peserta dinyatakan siap melaksanakan tugas praktik pengalaman lapangan (Ristekdikti, 2017).

Workshop SSP dalam model kolaboratif Program PPG di UM dan Unesa belum secara menyeluruh menerapkan Technological Pedagogical Content Knowledge (TPACK) dalam proses pembelajarannya. Hal ini berdampak pada lulusan yang masih belum dapat membuat media 
pembelajaran dengan memanfaatkan teknologi berbasis digital. Selama proses Program PPG, sebagian besar peserta mengembangkan media pembelajaran menggunakan teknologi yang masih bersifat konvensional. Sementara itu, perkembangan teknologi menuntut pembelajaran dilakukan dengan lebih efisien dan efektif agar tujuan pembelajaran dapat tercapai.

Pembelajaran abad 21 juga memiliki tuntutan agar peserta didik dapat memanfaatkan teknologi dalam pembelajaran. Berdasarkan hal tersebut, perlu perlu adanya pengembangan TPACK dalam tahap workshop SSP. Koehler, Mishra, Ackaoglu \& Rosenberg (2013) menjelaskan bahwa TPACK merupakan sebuah kerangka untuk mengintegrasikan teknologi dalam mengajar. TPACK memiliki tiga elemen utama, yaitu Technological Knowledge (TK), Content Knowledge (CK), dan Pedagogical Knowledge (PK) serta interaksi antara dua pengetahuan tersebut dan diantara tiga pengetahuan tersebut.

Kerangka TPACK berfungsi sebagai konsep dan teori bagi para peneliti dan pendidik untuk mengukur kesiapan calon guru dan guru dalam mengajar secara efektif dan efisien dengan memanfaatkan teknologi. Rasyid (2016) menegaskan bahwa calon guru dan guru dihadapkan pada tantangan besar dalam pergeseran perubahan teknologi, pedagogi, materi pembelajaran, dan konteks kelas saat ini. Guru sudah seharusnya lebih aktif menjadi desainer kurikulum dan bukan sekadar pengguna kurikulum yang telah ada.

Berdasarkan latar belakang dan masalah yang telah dipaparkan sebelumnya, artikel ini berusaha menguraikan dan mengkaji lebih mendalam tentang "Implementasi Framework TPACK dalam workshop SSP Program PPG untuk Meningkatkan Kompetensi Guru Geografi Profesional."

\section{B. METODE PENELITIAN}

Penelitian ini merupakan penelitian deskriptif menggunakan pendekatan kualitatif dengan desain studi kasus. Bogdan dan Biklen (1998) menegaskan bahwa tujuan penelitian kualitatif adalah mencari tahu suatu fenomena secara alamiah/natural secara detail dan sesuai dengan kenyataan yang ada. Artikel ini mengkaji kasus yang terjadi di Universitas Negeri Malang (UM) dan Universitas Negeri Surabaya (Unesa) pada Prodi Pendidikan Geografi. Data dalam penelitian ini terdiri dari data primer dan data sekunder. Data primer dalam penelitian ini adalah informan kunci, dan data sekunder adalah dokumen tentang Program PPG. Teknik pengumpulan data melalui wawancara mendalam dan dokumentasi. Analisis 
data menggunakan model interaksi Miles dan Huberman (1992). Pengujian keabsahan data yang diperoleh dari informan menggunakan teknik triangulasi data (sumber data).

\section{PEMBAHASAN}

Hasil penelitian lapangan berupa Model Kolaboratif Program PPG (Ningsih, 2016) menunjukkan bahwa dalam tahap kegiatan workshop SSP terdapat dua kegiatan utama, yaitu diskusi kelompok dan kerja kelompok/mandiri. Diskusi kelompok dilakukan bersama dosen di kelas untuk memperdalam materi pedagogik dan bidang geografi. Pada kegiatan ini, pemberian materi oleh dosen belum menyentuh ranah TPACK. Kegiatan ini bermanfaat untuk membangun kemampuan peserta Program PPG dalam menyusun media pembelajaran (bagian dari perangkat pembelajaran) dengan memanfaatkan teknologi digital.

Selama ini, peserta Program PPG belum maksimal mengolaborasikan pemanfaatan media pembelajaran berbasis teknologi digital dengan pengetahuan pedagogis dan konten pembelajaran Geografi. Namun, peserta Program PPG dituntut untuk dapat menghadapi Revolusi Industri 4.0 dalam dunia pendidikan yang ditandai dengan berkembang pesatnya kecerdasan buatan. Oleh karena itu, diperlukan framework TPACK dalam pembelajaran workshop SSP agar peserta Program PPG mampu menyiapkan perangkat pembelajaran yang dapat menjawab tujuan pembelajaran sesuai dengan tuntutan pembelajaran abad 21.

Koehler, Mishra, Ackaoglu \& Rosenberg (2013) menyampaikan bahwa terdapat tiga kajian pengetahuan utama dalam TPACK, yaitu Technological Knowledge, Content Knowledge, dan Pedagogical Knowledge serta interaksi antara masing-masing tiga kajian pengetahuan utama tersebut. Interaksi antar tiga kajian pengetahuan utama tersebut adalah Pedagogical Content Knowlage (PCK), Technological Content Knowlage (TCK) dan Teknological Pedagogical Knowlage (TPK). Pengembangan selanjutnya dari tiga unsur utama ini adalah TPACK yang mengolaborasikan pengetahuan, konten pembelajaran, dan teknologi.

Tiga unsur kajian pengetahuan utama dibangun dalam kegiatan diskusi kelompok dan kerja kelompok/mandiri. Dalam diskusi kelompok, peserta melakukan kegiatan diskusi materi geografi dan pedagogik yang belum dipahami. Pelaksanaan diskusi materi geografi di UM dan Unesa memiliki kolaborasi, yakni disampaikan sesuai dengan kebutuhan di lapangan (Ningsih, 2016). Peserta PPG tidak hanya belajar berkurikulum 2013, tetapi juga pendalaman materi. Hal ini menjadi 
kekuatan peserta Program PPG untuk siap mengajar dengan berbagai bentuk kurikulum yang diterapkan di Indonesia. Hal ini sesuai dengan informasi dari informan Asis berikut.

"Kita menjalani workshop SSP selama 6 bulan. Pada saat workshop rutinitasnya pendalaman materi dan praktek penyusunan perangkat pembelajaran. UM tidak mengacu untuk ber-K13 SMA, tetapi mahasiswa diajari untuk memahami dasar setiap kurikulum. Dasar konsep kurikulum ini berkaitan dengan dasar konsep materinya. Materi kita seperti mata kuliah. Meskipun berubah-ubah kurikulumnya, kita tetap punya pemahaman tentang materi dasarnya."

(UM/PSRT/ASS/A1/W/20.02.2016)

Kerja kelompok/mandiri yaitu menyusun perangkat pembelajaran geografi (silabus, RPP, media pembelajaran, bahan ajar, LKS, dan penilaian yang beracuan kepada kurikulum 2013). Model kolaboratif Program PPG menunjukkan bahwa pelaksanaan kerja kelompok/mandiri selalu dipantau oleh dosen sebagai fasilitator saat peserta mengalami kesulitan mengenai konten materi maupun pedagogik. Hal ini sesuai dengan pernyataan beberapa peserta PPG yang memiliki kesamaan informasi yaitu Munawaro, Ifa Dahtania P., dan Riska berikut.

"Saat workshop, kita menyusun perangkat didampingi dosen dan bisa bertanya jika kita memiliki kesulitan dalam memahami materi tertentu." (UNESA/PSR/MNR/A1/W/13.03.2016)

"Selama workshop itu, awalnya pembelajaran, lalu pendalaman materi dalam kegiatan praktek workshop. Disela-sela SSP ada pendalaman materi." (UNESA/PSR/IDP/A1/W/12.03.2016)

"Kita praktek SSP yaitu membuat perangkat mengajar selama 1 minggu yang terdiri dari silabus hingga RPP. Selama praktek ada dosen yang mendampingi, sehingga kita dapat bertanya ketika ada materi yang belum dipahami." (UNESA/PSR/RSK/A1/W/13.03.2016)

Pengintegrasian tiga unsur pengetahuan utama, yaitu teknologi, pengetahuan, dan pedagogik tersebut dikembangkan menjadi sebuah framework yaitu TPACK. Pemanfaatan teknologi digital dalam pembelajaran menjadi sebuah kebutuhan untuk menyampaikan konten pembelajaran geografi melalui metode pembelajaran 
yang sesuai dengan tujuan pembelajaran yang ingin dicapai. Peserta Program PPG perlu memahami dan menekankan pengintegrasia teknologi dalam praktek pembelajaran geografi. Rasyid (2016) menyampaikan bahwa ada dua pendekatan yang bisa dilakukan untuk menerapkan framework TPACK dalam pembelajaran, yaitu learning technology by design dan learning technology by activity types.

Sejalan dengan yang disampaikan Rasyid (2016), Koehler dan Mishra (2005) menyampaikan bahwa learning technology by design adalah proses belajar para guru tentang teknologi pendidikan dengan terlibat dalam tugas desain otentik pada kelompok kolaboratif kecil. Selanjutnya, Hofer \& Grandgenett dalam Hofer \& Harris (2010) menjelaskan terkait learning technology by activity types sebagai sebuah konsep untuk merancang pelajaran, proyek, dan unit yang diperkaya secara teknologi selama proses perencanaan yang dapat membantu para guru membangun pengetahuan untuk mengintegrasikan teknologi dengan kurikulum. Hal ini sesuai dengan kegiatan workshop SSP yaitu gabungan pleno 3, revisi, dan persetujuan RPP yang dilakukan dalam kegiatan peer teaching internal dan peer teaching eksternal.

Kegiatan peer teaching menjadi bagian terpenting dalam workshop SSP setelah peserta Program PPG menyelesaikan penyusunan perangkat pembelajaran geografi. Peserta Program PPG melakukan pemaparan hasil perangkat pembelajaran melalui skenario peer teaching internal lalu dievaluasi oleh dosen sebagai evaluator. Selanjutnya, peserta Program PPG juga melakukan pemaparan hasil perangkat pembelajaran melalui skenario peer teaching eksternal lalu dievaluasi oleh dosen dan guru dari sekolah mitra PPL sebagai evaluator. Peserta Program PPG mendapat kesempatan untuk memaparkan dan mengevaluasi perangkat pembelajaran yang sebelumnya telah disusun sehingga hasil perbaikan perangkat siap digunakan dalam tahap PPL di sekolah mitra. Informasi tersebut sejalan dengan yang disampaikan oleh peserta PPG Pendidikan Geografi yaitu Asis dan Yunita berikut.

"Ada peer teaching dengan teman-teman lalu diakhir tiap SSP ada microteaching yang mendatangkan guru pamong dari SMA PPL.” (UM/PSRT/ASS/A1/W/20.02.2016)

"Untuk peer teaching di bagi sesuai urutan SMA tempat PPL. Misalnya saya, saya dapatnya SMAN 8, nah pada minggu pertama yang peer teaching mereka yang PPL di SMAN 8. 
Jadi 5 anak ini yang melakukan peer teaching di minggu pertama. Begitu seterusnya selama enam bulan." (UM/PSR/KYA/A1/W/28.02.2016)

Pelaksanaan peer teaching menjadi muara untuk mempersiapkan perangkat pembelajaran yang akan digunakan pada kegiatan PPL di sekolah mitra. Penuturan peserta program PPG Pendidikan Geografi, pembelajaran yang dilakukan masih belum sepenuhnya menerapkan kerangka TPACK. Hal ini sesuai dengan penuturan Ifa Dahtania Palupi dan Asis berikut.

"Kemampuan memanfaatkan media yang sifatnya komputer atau digital masih kurang. Itu aja hanya sebagian kecil yang bisa buat video pembelajaran dan power point yang bisa gerak. Jadi kita sebagian besar buat media pembelajaran yang sifatnya manual.

(UNESA/PSR/IDP/A1/W/12.03.2016)

"Kita lebih banyak pendalaman ke materi karena dengan begitu apa pun kurikulumnya, kita tetap akan bisa ngajar karena sudah menguasai materi geografi dan pedagogiknya." (UM/PSRT/ASS/A1/W/20.02.2016)

Berdasarkan penuturan peserta Program PPG di atas, ditemukan bahwa calon guru belum sepenuhnya memiliki kemampuan untuk menyusun pembelajaran dengan memanfaatkan media pembelajaran berbasis teknologi dan mengolaborasikannya dalam pembelajaran. Hal ini berbanding terbalik dengan penerapan di lapangan yang menunjukkan bahwa guru geografi memerlukan kemampuan dalam menyusun perangkat pembelajaran berbasis teknologi yang sesuai dengan kerangka TPACK. Hal ini berarti pembelajaran workshop SSP dalam penyusunan perangkat pembelajaran geografi juga perlu membangun kemampuan guru untuk melakukan pembelajaran dengan kerangka TPACK.

Pemanfaatan teknologi dalam pembelajaran perlu dikembangkan untuk membangun kompetensi guru geografi profesional sejalan dengan tuntutan pembelajaran abad 21 dan perkembangan Revolusi Industri 4.0. Penerapannya dapat dimulai dari mendesain pembelajaran Program PPG geografi dengan memanfaatkan teknologi dari yang sederhana menuju teknologi digital yang lebih mutakhir. Peserta Program PPG perlu dibekali dengan kemampuan mendesain perangkat pembelajaran yang di dalamnya terdapat kolaborasi penggunaan teknologi yang sesuai dengan konten materi, metode, dan model pembelajaran. 
Konten materi geografi memiliki kekhasan yaitu bersifat kontekstual terkait fenomena alam dan sosial serta interaksi antara keduanya. Konten materi geografi memerlukan pengkonkritan dan perwujudan di ruang kelas terutama yang bersifat teoretis. Selain itu, konten materi yang bersifat konkret memerlukan media pembelajaran yang dapat membangun pemahaman siswa agar dapat mengaitkan antara teori dengan kondisi lapangan. Selama program PPG berlangsung, peserta Program PPG umumnya menyajikan konten materi geografi melalui media digital sederhana berupa PPT. Peserta belum mengolaborasikan materi pembelajaran dengan penggunaan teknologi berbasis digital yang lebih kompleks.

Pembelajaran TPACK dapat diterapkan melalui sistem pembelajaran blended learning. Pembelajaran blended learning mengolaborasikan kegiatan pembelajaran di dalam kelas dengan ruang maya yang memanfaatkan teknologi internet. Hal ini senada dengan Bonk dan Graham (2005) yang menyampaikan bahwa sistem blended learning menggabungkan instruksi tatap muka dengan instruksi yang dimediasi komputer.

Peserta Program PPG Pendidikan Geografi perlu mendapat pembekalan keahlian dalam memanfaatkan blended learning untuk menunjang pembelajaran di ruang-ruang kelas. Husamah (2014) menegaskan bahwa mengembangkan mata kuliah berbasis blended learning sejalan dengan adanya tantangan unik yaitu teknologi, strategi pembelajaran, cara baru berkomunikasi, dan asesmen. Pembelajaran dalam sistem blended learning dapat didesain dengan berbagai jenis model dan metode pembelajaran yang akan digunakan untuk memfasilitasi peserta didik melakukan pembelajaran baik secara on class maupun off class.

Blended learning memfasilitasi peserta didik untuk mempelajari materi geografi yang terdiri dari materi abstrak dan konkret. Materi pembelajaran geografi dapat berupa teks, power point, animasi flash, video pembelajaran, dan share link ke ruang digital blanded learning yang berbasis web atau aplikasi android. Bentuk materi pembelajaran geografi tersebut berupa tampilan visual, audio, dan audio visual. Tampilan materi pembelajaran yang demikian dapat memudahkan penyampaian materi yang sifatnya abstrak dan konkret. Selain itu, materi tersebut dapat dimunculkan dalam suatu ruang pembelajaran digital blended learning yang telah ada atau menciptakannya sendiri.

Selain berisi materi, ruang digital blended learning juga dapat dilengkapi dengan media conference untuk wadah diskusi antara siswa dan guru. Ruang 
digital blended learning yang ada saat ini yaitu Edmodo, Google Clasroom, Moodle, dan sosial media (facebook, twitter, instagram, dan youtube). Masing-masing ruang digital tersebut memiliki keunggulan dan kekurangan sehingga peserta Program PPG dapat menggunakannya dengan menyesuaikan kebutuhan dan capaian tujuan pembelajaran. Selain itu, guru dan calon guru geografi juga dapat menciptakan ruang digital blended learning berbasis aplikasi yang dapat diunduh dan dibuka melalui gawai seperti aplikasi MoLearn (Mobile Learning).

Pemanfaatan blended learning dalam pembelajaran dapat membantu peserta Program PPG Pendidikan Geografi yang merupakan calon guru geografi untuk lebih efisien dan efektif menyampaikan materi geografi kepada peserta didik. Hal ini senada dengan hasil penelitian Irmawati, Sriyono dan Santoso (2013) yang menyatakan bahwa pelaksanaan pembelajaran dengan blended learning model berbasis web sebagai sumber belajar lebih baik daripada pembelajaran model konvensional dalam materi hidrosfer pada siswa kelas X SMA Negeri 1 Parakan Kabupaten Temanggung tahun ajaran 2011/2012. Hal ini dibuktikan dengan adanya peningkatan hasil belajar geografi materi hidrosfer setelah penggunaan blended learning model berbasis web dibandingkan model pembelajaran konvensional.

Kegiatan penyampaian materi geografi oleh peserta Program PPG direncanakan dalam penyusunan perangkat pembelajaran. Kegiatan tersebut dilakukan oleh peserta Program PPG dalam tahapan workshop SSP pada kegiatan kerja kelompok/mandiri. Pada kegiatan ini, peserta PPG perlu dilatih untuk merencanakan kolaborasi kegiatan pembelajaran di kelas dan melalui ruang digital blended learning dalam perangkat pembelajaran masing-masing. Kemudian, perangkat pembelajaran tersebut diujicobakan dalam kegiatan selanjutnya yaitu peer teaching internal dan eksternal hingga menghasilkan perangkat yang sesuai dengan tujuan pembelajaran dan kebutuhan di lapangan serta membangun pembelajaran yang bermakna untuk peserta didik.

Pembelajaran bermakna merupakan suatu proses dimana siswa dapat membangun dan mengaitkan berbagai pengetahuan yang telah diperoleh sebelumnya untuk dapat menyelesaikan permasalahan (problem solving). Anderson dan Krathwohl (2010) menegaskan bahwa pembelajaran bermakna terjadi jika di dalamnya terdapat proses siswa membangun pengetahuan dan di dalamnya siswa berusaha memahami pengalamanpengalaman yang pernah mereka alami. Guru memiliki kewajiban mengarahkan 
siswa agar tidak hanya menerima

mengimplementasikan

kerangka

pengetahuan, tetapi juga mendapatkan

TPACK (Technological Pedagogical

keterampilan untuk memecahkan

Content Knowledge) untuk

masalah di lingkungan sekitar mereka.

Hal ini senada dengan yang disampaikan

oleh Darmawan dan Sujoko (2013)

bahwa saat siswa membangun

pengetahuan dan terjadi proses kognitif yang diperlukan untuk memecahkan masalah maka pada saat itu sedang terjadi belajar bermakna.

Husamah (2014) menyatakan bahwa blended learning bertujuan untuk mendapatkan pembelajaran yang "paling baik". Hal ini dikarenakan pembelajaran blended learning menggabungkan berbagai keunggulan masing-masing komponen baik metode konvensional maupun modern berbasis teknologi digital. Metode konvensional memungkinkan guru melakukan pembelajaran secara interaktif melalui tatap muka dengan siswa. Metode modern berbasis digital dapat dilakukan guru dengan memberikan materi secara online tanpa batasan ruang dan waktu sehingga dapat dicapai pembelajaran yang maksimal. Oleh karena itu, kegiatan workshop SSP dalam Program PPG Pendidikan Geografi perlu menerapkan pembelajaran TPACK untuk menyiapkan guru geografi yang kompeten dan profesional.

\section{KESIMPULAN}

$\begin{array}{cccc} & \text { Pembelajaran } & \text { workshop } & \text { SSP } \\ \text { dalam } & \text { Program } & \text { PPG } & \text { perlu }\end{array}$




\section{E. DAFTAR PUSTAKA}

Anderson, Lorin W., Karthwohl, David

R., (2008). Kerangka Landasan

Untuk Pembelajaran,

Partnership for 21st Century

Skill. "21st Century Skills,

Education \& Competitiveness:

A RESOURCE AND POLICY

GUIDE." Arizona: e-Luminate

Group Pelajar, 2010, 46.

Bogdan, Robert C. Biklen \& Knopp,

Sari. 1982. Qualitative Research

for Education: and Introduction

to Theory and Methods. Boston:

Allyn \& bacon Inc.

Bonk, Curtis J., Graham, Charles R.

(2005). The Handbook of

Blended Learning: Global

Perspectives, Local Designs.

United State of America:

Pfeiffer A Wiley Imprint.

Darmawan, I. P., Sujoko, E. (2013).

Revisi Taksonomi Pembelajaran

Benyamin S. Bloom. Satya

Widya, 29 (1), 30-39.

https://doi.org/https://doi.org/10.

24246/j.sw.2013.v29.i1.p30-39

Hidayat, Esa Wahyu., Utami, Wiwik Sri.

(2019). Kajian Mata Pelajaran

Geografi Sebagai Bekal Peserta

Didik Untuk Menghadapi

Tuntutan Pembelajaran Abad 21

Di SMA Surabaya. Jurnal

Pendidikan Geografi, 1(1).

https://jurnalmahasiswa.unesa.ac .id/index.php/swara-

bhumi/article/view/26832/24556

Hofer, M., Harris, J. (2010).

Differentiating

TPACK

development: Using Learning

Activity Types With Inservice and Preservice Teachers. In C.

D. Maddux, D. Gibson, \& B.

Dodge (Eds.). Research

Highlights in Technology and

Teacher Education 2010 (pp.

295-302). Chesapeake, VA:

Society for Information

Technology and Teacher

Education.

Hoyles, C., Lagrange, J.-B. (Eds.). (2010). Mathematics Education and Technology - Rethinking The Terrain. New York, NY/Berlin, Germany: Springer.

Husamah. (2014). Pembelajaran Bauran (Blended Learning) Terampil Memadukan Keunggulan Pembelajaran Face-to-Face, Elearning Offline-Online dan Mobile Learning. Malang: Prestasi Pustaka Publisher.

Kementrian Ristekdiktii. (2016). Undang-Undang RI No. 20 Tahun 2003 tentang Sistem Pendidikan Nasional. Jakarta: Kelembagaan Ristekdikti. Diakses dari https://kelembagaan.ristekdikti.g o.id/wp- 
content/uploads/2016/08/UU no _20_th_2003.pdf.

Kementrian Ristekdikti. (2017). Pedoman Penyelenggaraan Program Pendidikan Profesi Guru 2017. Jakarta, Direktorat Jenderal Pembelajaran dan Kemahasiswaan Kementeritan Ristekdikti. Diakses dari https://kelembagaan.ristekdikti.g o.id/wp-

content/uploads/2017/08/Pedom an-Penyelenggaraan-PPG.pdf.

Koehler, M. J., Mishra, P., Ackaoglu, M., \& Rosenberg, J. M. (2013). The Technological Pedagogical Content Knowledge Framework for Teachers and Teacher Educators. Commonwealth Educational Media Centre for Asia.

Koehler, Matthew J., Mishra, Punya. (2005). Teachers Learning Technology by Design. Journal of Computing in Teacher Education, 21(3), 94-102. https://www.tandfonline.com/do $\mathrm{i} / \mathrm{abs} / 10.1080 / 10402454.2005 .1$ $\underline{0784518}$

Ningrum, Epon. (2007). Pemetaan Kualifikasi dan Kompetensi Guru Geografi Bagi Peningkatan Profesionalitas. Bandung: Universitas Pendidikan Indonesia.
Ningsih, Mega Prani. (2016). Implementasi Program PPG dalam Membangun Kompetensi Guru Geografi (Studi Multi Situs di UM dan Unesa pada Peserta Alumni SM 3T). Tesis. Pendidikan Geograf, Program Pascasarjana, Universitas Negeri Malang

Putrawangsa, S., \& Hasanah, U. (2018). Pengajaran, dan Asesmen: Revisi Taksonomi Pendidikan Bloom. "Pustaka INTEGRASI TEKNOLOGI DIGITAL DALAM PEMBELAJARAN DI ERA INDUSTRI 4.0." Jurnal Tatsqif, $\quad 16(1), \quad 42-54$. https://doi.org/10.20414/jtq.v16i $\underline{1.203}$

Rosyid, Abdul. "Technological Pedagogical Content Knowledge: Sebuah Kerangka Pengetahuan bagi Guru Indonesia di Era MEA.” Prosiding Seminar Nasional Inovasi Pendidikan Inovasi Pembelajaran Berbasis Karakter dalam Menghadapi Masyarakat Ekonomi ASEAN. Surakarta: Universitas Negeri Surakarta, 2016. 446-454. Cetak.

Trilling, Bernie., Fadel, Charles. (2009). 21st Century Skills: Learning for Life in Our Times, John Wiley \& Sons, 978-047-0553626. 